\title{
Editorial
}

\section{Safety at Level Crossings}

\author{
El Miloudi El Koursi ${ }^{1, \S}$, Louahdi Khoudour ${ }^{2, \S}$ and Marc Heddebaut ${ }^{*}, 2, \S$ \\ ${ }^{I}$ IFSTTAR-ESTAS, French Institute of Sciences and, Technology for Transport, Development and Networks, France \\ ${ }^{2}$ IFSTTAR-LEOST, French Institute of Sciences and Technology for Transport, Development and Networks, France \\ ${ }^{\S}$ Guest Editor
}

Every year, more than 400 people are killed in over 1200 accidents at road-rail level crossings in the European Union. Together with tunnels and specific road black spots, level crossings (LC) have been identified as being a particular weak point in road infrastructure, seriously jeopardizing road safety. Safety at LC is a single part of a wider picture of transport safety within the whole transport system. For many years, governments as well as the rail industry and road organizations have been implementing a variety of countermeasures to improve railway level crossing safety. Despite the fact that these actions are substantial and have resulted in a continuing decrease in the number and the severity of level crossing accidents, LC are still identified as being a weak point in road infrastructure, seriously jeopardizing road safety. This constitutes a difficult problem to be solved by Rail companies. Indeed, they cannot control the actions of road vehicle drivers and pedestrians at level crossings.

This special issue focuses on safety at level crossings and provides a wide picture on the development of new approaches and technologies to improve safety at level crossings. The papers presented in this special edition reflect the scientific multidisciplinary topic of level crossing. These contributions can be classified into three categories: Appraisal, modeling and technology.

A. Janota's paper discusses the problem of safety of Slovak level crossings, seen through the statistical data, and explains distinctive features identified on the base of comparison with level crossings operated in other EU countries. It deals with a knowledge-based approach applied to diagnosis of electronic/computer-based level crossing installations.

A. Berrado's paper introduces a risk management framework that allows to understand and to assess the risks associated with a given level crossing. The suggested framework involves several activities, including, hazard identification, risk analysis, evaluation, treatment, and control. It illustrates how it can be systematically applied to mitigate risk at a given Moroccan level crossing.

*Address correspondence to this author at the IFSTTAR-LEOST, French Institute of Sciences and Technology for Transport, Development and Networks, France; Tel: 333204383 13; Fax: 3332043 83 97;

E-mail: marc.heddebaut@ifsttar.fr
N. Fakhfakh's paper on "A video-based object detection system" aims to improving safety at LC. The contribution provides a possible technological solution to reduce the number of accidents at level crossings and discuss the effectiveness of the use of video sensing for 3D object detection.

F. Deffossez's paper completes this approach by developing a formal methodology to analyze the safety of discrete time process that can be applied to level crossings.

Safety at level crossings is also a major concern at Finnish railways and Dr. Kallberg's paper deals with the sight distance requirements for Finnish LC. This is particularly critical since less than a quarter of all level crossings are equipped with active warning devices, not only barriers but also warning lights and bells. Especially at passive level crossings, it is entirely up to the road user to know whether it is safe or not to cross the railway. The author discusses the formulation of safety guidelines for Finnish level crossings, conducted at VTT "Technical Research Centre" for the Finnish Rail Administration.

Dr. Kallber's paper on Safety audits of Finnish level crossings for 10 years presents a number of recommendations for safety measures to improve safety.

This special issue concludes with the contribution prepared by Dr. J. Luoma who investigates how drivers can understand safe behavior and perceive risks at passive railway-road level crossings. Fifty-six cars and van drivers were interviewed after passive level crossings with low traffic volume. These results suggest that a substantial percentage of drivers have no appropriate concept of safe behavior at level crossings. Another important result presented is that drivers found the crossing of main roads to be more difficult than crossing passive railway-road level crossings - despite the fact that they considered the latter to be more dangerous. This also suggests that drivers estimate that crash risk at railway-road level crossings is relatively low, although they know that it is dangerous in general. Furthermore, the investigated drivers suggested that the conspicuity of level crossings could be improved by 
increasing lateral visibility early enough and with advance warning signs.

Above all, we hope that this selection of papers demonstrates the degree of science, engineering and technology now being employed in a railway process to improve safety at level crossings.

(C) El Koursi et al.; Licensee Bentham Open.

This is an open access article licensed under the terms of the Creative Commons Attribution Non-Commercial License (http://creativecommons.org/licenses/by-nc/ $3.0 /$ ) which permits unrestricted, non-commercial use, distribution and reproduction in any medium, provided the work is properly cited. 